\title{
Toxicity evaluation of process water from hydrothermal carbonization of sugarcane industry by-products
}

\author{
Laís Gomes Fregolente ${ }^{1}$. Thaiz Batista Azevedo Rangel Miguel ${ }^{2}$. Emilio de Castro Miguel ${ }^{3}$. \\ Camila de Almeida Melo ${ }^{1}$ - Altair Benedito Moreira ${ }^{1}$. Odair Pastor Ferreira ${ }^{2} \cdot$ Márcia Cristina Bisinoti $^{1}$
}

Received: 15 November 2017 / Accepted: 13 March 2018

(C) Springer-Verlag GmbH Germany, part of Springer Nature 2018

\begin{abstract}
Hydrothermal carbonization (HTC) is a thermochemical process carried out in an aqueous medium. It is capable of converting biomass into a solid, carbon-rich material (hydrochar), and producing a liquid phase (process water) which contains the unreactive feedstock and/or chemical intermediates from the carbonization reaction. The aim of this study was to evaluate the characteristics of process water generated by HTC from vinasse and sugarcane bagasse produced by sugarcane industry and to evaluate its toxicity to both marine (using Artemia salina as a model organism) and the terrestrial environment (through seed germination studies of maize, lettuce, and tomato). The experiments showed that concentrated process water completely inhibited germination of maize, lettuce, and tomato seeds. On the other hand, diluted process water was able to stimulate seedlings of maize and tomato and enhance root and shoot growth. For Artemia, the $\mathrm{LC}_{50}$ indicated that the process water is practically non-toxic; however, morphological changes, especially damages to the digestive tube and antennas of Artemia, were observed for the concentration of $1000 \mathrm{mg} \mathrm{C} \mathrm{L}^{-1}$.
\end{abstract}

Keywords Germination $\cdot$ Maize $\cdot$ Lettuce $\cdot$ Tomato $\cdot$ Seedling growth $\cdot$ Artemia salina $\cdot$ Bioassay

\section{Introduction}

Hydrothermal carbonization (HTC) is a process used to convert biomass into carbon-rich materials (hydrochar) (Yoshimura and

Responsible editor: Philippe Garrigues

Electronic supplementary material The online version of this article (https://doi.org/10.1007/s11356-018-1771-2) contains supplementary material, which is available to authorized users.

Márcia Cristina Bisinoti

bisinoti@ibilce.unesp.br

1 Departamento de Química e Ciências Ambientais, Laboratório de Estudos em Ciências Ambientais, Instituto de Biociências, Letras e Ciências Exatas, UNESP, Universidade Estadual Paulista, Campus São José do Rio Preto, Cristóvão Colombo Street, 2256, São José do Rio Preto, São Paulo State 15054-000, Brazil

2 Laboratório de Materiais Funcionais Avançados (LaMFA), Departamento de Física, Universidade Federal do Ceará, P.O. Box 6030, Fortaleza, Ceará State 60455-900, Brazil

3 Central Analítica, Universidade Federal do Ceará, P.O. Box 6030, Fortaleza, Ceará State 60455-900, Brazil
Byrappa 2008; Libra et al. 2011; Kambo and Dutta 2015); however, it also generates a liquid phase (process water) (Tekin et al. 2013; Poerschmann et al. 2014). Several sources of biomass, such as starch, sewage sludge, wood, municipal waste, agricultural waste, and general industry wastes have been used for HTC (Libra et al. 2011; Parshetti et al. 2013; Tekin et al. 2013). The characteristics of the hydrochar generated in HTC depend on the feedstock used as well as the reaction parameters, such as temperature, reaction time, and $\mathrm{pH}$ of the medium during the hydrothermal process (Libra et al. 2011; Bargmann et al. 2014; Vozhdayev et al. 2015). Hydrochar has been used both as a source of energy and as solid fuel (Funke and Ziegler 2010; Oliveira et al. 2013). Therefore, it can also be served as a source of nutrients for soils (Rillig et al. 2010; Libra et al. 2011; Du et al. 2012). The energetic evaluation of the HTC process to convert biomass into a solid material showed to be positive; however, it will depend on the feedstock, the ratio of dry biomass to water, and also the carbonization process parameters as temperature and reaction time (Stemann and Ziegler 2011; Stemann et al. 2013; Lucian and Fiori 2017).

Previous studies to assess the toxic effect of hydrochar have focused on experiments with plants, in particular, 
evaluating the germination processes (Bargmann et al. 2013; Fang et al. 2015) and growth (Rillig et al. 2010; Reibe et al. 2015) as well as study the changes caused in the soil biota by hydrochar (George et al. 2012; Salem et al. 2013; Melo et al. 2017c). Process water recirculation in the new HTC process has been reported in the literature as its main use ( $\mathrm{Lu}$ et al. 2014; Weiner et al. 2014; Kabadayi Catalkopru et al. 2017). However, the process water also has been evaluated as a culture medium for algal growth (Biller et al. 2012; Hognon et al. 2015), in seed germination studies (Bargmann et al. 2013; Vozhdayev et al. 2015), and recently using Artemia salina to assess its toxic effects (Melo et al. 2017c).

The amount of waste produced by sugarcane industry as well as the lack of a suitable method for disposal of the resulting waste without causing environmental damage led Melo et al. (2017a) to propose the use of these residues in hydrothermal carbonization. Vinasse is the liquid residue generated in the process to obtain ethanol, wherein, for each liter of ethanol produced, 10 to $18 \mathrm{~L}$ of vinasse is generated. Vinasse is an aqueous solution, rich in organic matter with high concentrations of potassium, sodium, calcium, magnesium, and other elements (Christofoletti et al. 2013; Marinho et al. 2014; Moraes et al. 2015). The sugarcane bagasse is basically composed of cellulose, hemicellulose, and lignin (Rezende et al. 2011). Nowadays, vinasse is used in fertigation and sugarcane bagasse is used as fuel in cogeneration of energy (de Souza Dias et al. 2015). The application of sugarcane in fertigation can cause some problems as soil salinization and groundwater contamination (Bueno et al. 2009; De Oliveira et al. 2013). The development of "stable fly" which is a kind of fly that feeds by bovine blood is related to the areas which vinasse is applicated and also near sugarcane mills (Cançado et al. 2013; Jelvez Serra et al. 2017). This fly provokes damage to cattle breeding as weight losses in bovine and decrease in the amount of milk produced. The use of vinasse to produce biogas through biodigestion has also been reported intending to save sugarcane bagasse for second generation ethanol production (Joppert et al. 2017). Sugarcane bagasse has mainly been used for energy cogeneration (Hofsetz and Silva 2012; de Souza Dias et al. 2015), but researches are trying to find a more environmental friendly way for sugarcane bagasse disposal. Studies have been developed to evaluate sugarcane bagasse to produce bioethanol, biodiesel, biopolymers among others (Sindhu et al. 2016). Trying to find an alternative use for sugarcane by-products, that would be able to be more or equal attractive economically as the ways that they are already applied, hydrothermal carbonization process was evaluated using vinasse and sugarcane bagasse. The use of vinasse as a hydrothermal medium and sugarcane bagasse as a biomass source led to the production of hydrochar which showed potential for application as a soil conditioner (Melo et al. 2017a; Silva et al. 2017).
However, previous studies did not demonstrate the characteristics of the process water generated in the HTC of vinasse and sugarcane bagasse. Additionally, the process water toxicity was not evaluated. Thus, as reported in the literature, process water generated during the HTC of several biomasses presents different concentrations of carbon, phosphorus, potassium, and nitrate (Biller et al. 2012; Bargmann et al. 2013; Weiner et al. 2014) as well calcium and magnesium (Ross et al. 2010). Such characteristics indicate that process water has potential for agricultural applications such as use as fertilizers. However, it has also been reported that these waters contain, in general, phenols, organic acids, and furans. These are formed during the degradation process of biomass (Kambo and Dutta 2015) and may, on the other hand, cause some toxic effects on the development of plants.

Thus, the main objective of this study was to investigate the toxicity of process water generated in the HTC of vinasse and sugarcane bagasse to marine habitat, using Artemia salina as the model organism, and its toxicity to terrestrial environment through the study of germination and growth of maize, lettuce, and tomato seeds. Considering that process water is generated in large quantities in the hydrothermal carbonization process, this study will help understand the potential of process water from carbonization of vinasse and sugarcane bagasse to fertigation purposes, as a means of disposal and the other applications of this material.

\section{Experimental}

\section{Preparation and characterization of process water from HTC}

The reaction was processed as described by Melo et al. (2017a) using a stainless-steel reactor coated with Teflon ${ }^{\circledR}$ with a capacity of $600 \mathrm{~mL}$. The hydrothermal carbonization process was performed using $80 \%$ of the reactor capacity, employing sugarcane bagasse and vinasse as feedstock in the ratio of 1:20 followed by addition of phosphoric acid $(4 \% v / v)$. The reaction was carried out at $230{ }^{\circ} \mathrm{C}$ for $13 \mathrm{~h}$. After the reaction, the reactor was immersed in an ice bath to stop the reaction and then opened. The solid material was vacuum filter separated; the filtrate (PW) was stored at $4{ }^{\circ} \mathrm{C}$ and subsequently used in the toxicity tests.

Process water was characterized for $\mathrm{pH}$, turbidity (HI 93703, Hanna Instruments), color (HI 96727, Hanna Instruments), total organic carbon (TOC) (TOC-VCSN, Shimadzu), sulfate (Standard Methods $4500-\mathrm{SO}_{4}{ }^{-2}$ ), phosphorus (EMBRAPA 2000), and the determination of K, Ca, $\mathrm{Al}, \mathrm{Na}, \mathrm{Mg}, \mathrm{Mn}, \mathrm{Fe}, \mathrm{Zn}$, and $\mathrm{Cu}$ was made by Flame Atomic Absorption Spectrometric (FAAS) (AA240FS, Varian) in the samples previously decomposed by acid, method 3010A (US EPA 1992). 


\section{Toxicity assay}

\section{Seed germination and seedling growth}

Germination experiments were conducted using petri dishes and agar medium. Seeds (purchased commercially) of maize (Zea mays, Poaceae) (Seminis, $85 \%$ germination), lettuce (Lactuca sativa, Asteraceae) (Sakata, 95\% germination), and tomato (Solanum lycopersicum, Solanaceae) (Sakata, 95\% germination) were used. It was used $1 \mathrm{~g}$ of agar to each $100 \mathrm{~mL}$ of the solution to prepare the agar medium. "Solution" means deionized water and different dilutions of PW. The concentrated PW (sample D5) with a TOC of $25.190 \mathrm{~g} \mathrm{C} \mathrm{L}^{-1}$ was diluted to solutions containing 50, 100, 250, and $500 \mathrm{mg} \mathrm{C} \mathrm{L}^{-1}$ (samples D1, D2, D3, and D4, respectively, Table $\mathrm{S} 1$ ) and its $\mathrm{pH}$ was corrected to 5 (Bhattacharya and Khuspe 2001; Gonçalves et al. 2016).

The seeds were pre-treated with $10 \%$ sodium hypochlorite solution for $15 \mathrm{~min}$ and then exhaustively washed with distilled water. For these assays, 10 seeds were placed in each petri dish (15-cm diameter) with five replicates for each PW concentration and these were randomly placed in a B.O.D. germination chamber (MA 403, Marconi) at $25^{\circ} \mathrm{C}$, for 7 days and exposed to a photoperiod of 16-h light and 8-h dark-light cycles. The number of seeds germinated daily was recorded. The seeds were considered as germinated when a length of $0.5 \mathrm{~mm}$ or more of shoot or root emerged from the seed. From these results, the Germination Index (GI) was calculated as described in Eq. 1:

$\mathrm{GI}=\sum \frac{\mathrm{ni}}{\mathrm{ti}}$

where $\mathrm{ni}=$ "number of seeds germinated on the observation day" and ti= "observation day" (Maguire 1962; Silva and Matos 2016; Zhou et al. 2016).

At the end of the experiment, the total number of seeds germinated in each plate was counted. Root and shoot lengths of all germinated seeds were measured using ImageJ (version 1.51i) software in order to evaluate plant growth.

\section{Lethality of Artemia salina nauplii evaluation}

Artemia saline cysts (Maramar) were commercially purchased and preserved in their original packaging at room temperature $\left(24{ }^{\circ} \mathrm{C}\right)$. The cysts were incubated in glass bottles containing artificial seawater which was prepared with commercial sea salt mixture (Blue Treasure, Reef Sea Salt) and ultrapure water in the ratio of $0.20 \mathrm{~g}$ of cysts to $200 \mathrm{~mL}$ artificial seawater, as described by Meyer et al. (1982). Hatching occurred under the conditions of constant aeration and lighting for $48 \mathrm{~h}$.
Three concentrations of the PW according the amount of TOC (10, 100, and $\left.1000 \mathrm{mg} \mathrm{C} \mathrm{L}^{-1}\right)$ were obtained. The $\mathrm{pH}$ medium was adjusted to 8 . The acute toxicity evaluation was performed for Artemia salina nauplii for a period of $24 \mathrm{~h}$ of exposure. The experiments were carried out in cell culture plates ( 24 wells) to which nauplii were added per well. The animals did not receive food during the experiment which was performed in fivefold. The negative control consisted only of artificial seawater and 10 nauplii of Artemia. The analyses performed at the end of the experiment were conducted by comparing the conditions tested against the control.

The morphological changes and the accumulation of material in Artemia nauplii were observed by light microscopy (Leica DM 2500 microscope) in the light field (Madhav et al. 2017). After exposure to the environment of interest, the organisms were transferred to a glass plate and were observed in 200-fold magnification under the optical microscope.

For a more detailed analysis of nauplii, after exposure to process water, individuals were also submitted to scanning electron microscopy (SEM) analysis. The animals were fixed in a solution containing $2.5 \%$ glutaraldehyde and $4 \%$ formaldehyde in a buffer of $0.1 \mathrm{~mol} \mathrm{~L}^{-1}$ sodium cacodylate at $\mathrm{pH} 8$. The material was then dehydrated in an increasing series of acetone $(30,50,70,90$, and $100 \%)$ and dried with hexamethyldisilane. Finally, the samples were fixed in stubs with carbon adhesive tape, metallized with $20-\mathrm{nm}$ gold (Quorum QT150ES), and observed under a scanning electron microscope (Quanta FEG 450 - FEI) at a voltage of $20 \mathrm{kV}$.

After $24 \mathrm{~h}$, the data obtained from the lethality tests were processed using Microsoft Excel software and the $\mathrm{LC}_{50}$ values were calculated using the percentage of death and the log of the concentrations by Probit analysis, as described by Finney (1971). $\mathrm{LC}_{50}$ is the concentration of $\mathrm{PW}$ required to reduce $50 \%$ of the population of exposed animals.

\section{Statistical analyses}

The normality of the data was evaluated using normal probability plots of residuals, and the comparison between groups was performed using a general linear models (GLM), followed by Tukey's post hoc test. Results were considered statistically significant when $p$ value was $<0.05$.

\section{Results and discussion}

\section{Hydrothermal carbonization and characterization of process water}

The characteristics of sugarcane bagasse and vinasse used in this carbonization process are described by Melo et al. (2017a). The PW generated during the carbonization of 
vinasse and sugarcane bagasse exhibited a $\mathrm{pH}$ of $2.47 \pm 0.19$, color 20555 PCU, turbity 178 FTU, and the concentration of TOC was $25.19 \pm 3.56 \mathrm{~g} \mathrm{~L}^{-1}$. The $\mathrm{pH}$ value of $\mathrm{PW}$ was more acidic than found by Bargmann et al. (2013) in the process water from carbonization of spent brewer's grains and beetroot chips with addition of citric acid and calcium carbonate to the hydrothermal medium and also process water from grass, wood, wheat straw, corn silage among others where the hydrothermal media were composed only of water without acid. However, the $\mathrm{pH}$ of the $\mathrm{PW}$ is closer to that found by Weiner et al. (2014) for the process water generated by carbonization of paper where the hydrothermal medium was produced by a solution of $0.001 \mathrm{~mol} \mathrm{~L}^{-1}$ sulfuric acid. The organic carbon concentration in the PW is high when compared to that derived from carbonization of paper (Weiner et al. 2014); however, it is similar of that from carbonization of miscanthus (Kambo et al. 2017). The macros and micronutrients present in the PW used in this study are showed in Table S1. Sulfate concentration in the PW was $11.90 \pm 0.75 \mathrm{mg} \mathrm{L}^{-1}$ and phosphorus concentration was $168.11 \pm 9.62 \mathrm{mg} \mathrm{L}^{-1}$. The concentration of potassium in the PW (Table S1) was more than twofold of that found by Bargmann et al. (2013). This difference is attributed to the presence of vinasse in the hydrothermal carbonization carried out in this study because the concentration of potassium in vinasse and bagasse.

The comparisons mentioned above suggest the nonfeasibility of correlating the process water data obtained from different biomasses carbonizations indicating that the characteristics are distinct and dependent on the starting feedstock and the hydrothermal medium.

\section{Toxicity assay}

\section{Seed germination and seedling growth}

The number of germinated seeds (Fig. 1) was demonstrated as the percentage of germination for the diluted process waters. The results indicated that the presence of PW caused a delay in the germination process. However, a complete inhibition of germination was observed only for concentrated PW (D5) for all the seeds studied.

For maize seeds (Fig. 1), the D1 concentration, presented a behavior similar to the control, showing no delay in germination unlike the other concentrations. For lettuce, all the concentrations studied showed a delay in the germination process (Fig. 1). For tomato, the concentration D1 (Fig. 1) presented a behavior similar to control in the germination process. On the other hand, concentrations D2, D3, and D4 showed a delay in the germination process. Thus, for all seeds, there is an increase in the number of days required for the occurrence of germination with the increase of PW concentration, showing a delay effect in germination process influenced by the medium.
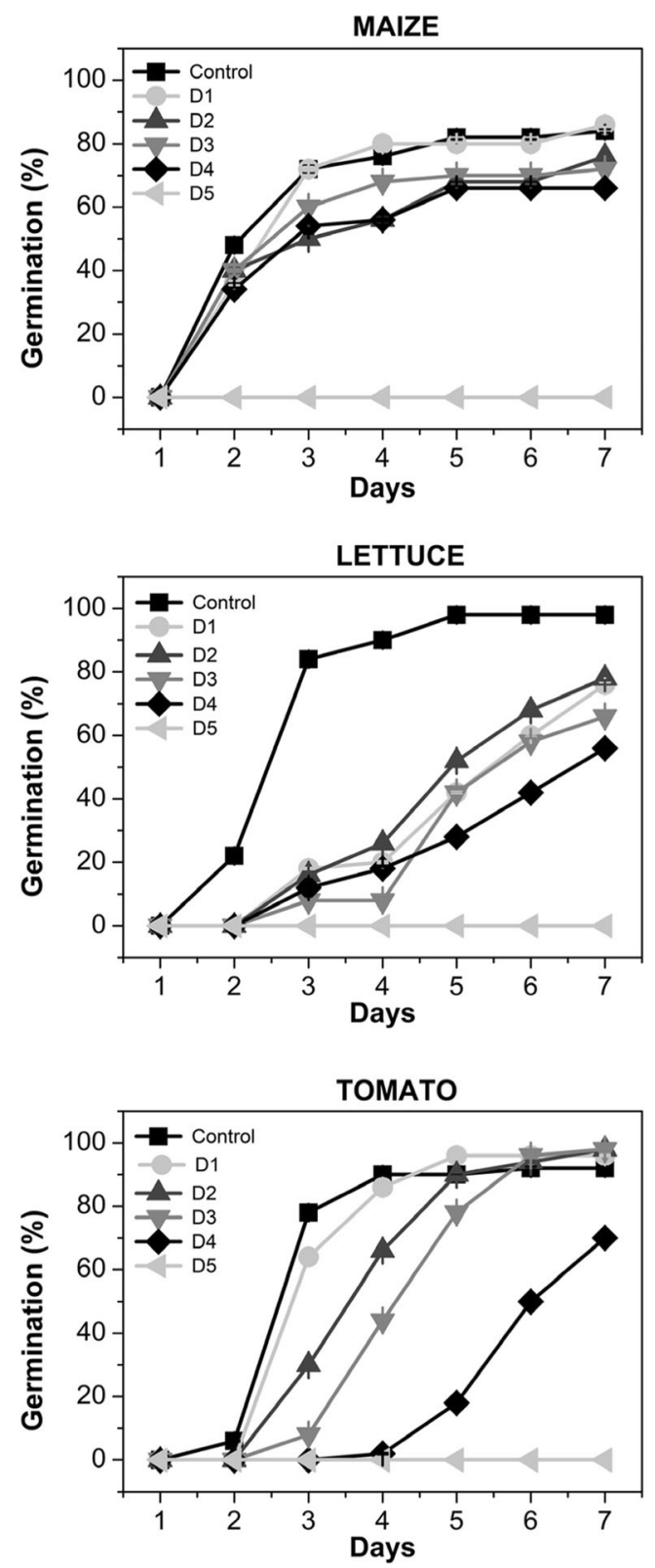

Fig. 1 Effect of process water concentration on germination percentage of maize, lettuce, and tomato seeds during 7 days

Figure 2 shows the total number of germinated seeds for each PW concentration at the end of the 7 days. Although there is no statistical difference for the final number of germinated seeds between the control and D1, D2, and D3 dilutions, there is a linear association between the final percentage of germinated seeds and the concentration of PW until concentration D3, and this trend is crescent for tomatoes and decrescent for maize and lettuce. Thus, for maize and lettuce, the increase of PW concentration in the medium leads to a reduction in the number of seeds germinated at the end of the experiment. For tomato, an increase in the number of seeds germinated was observed with the increase in the concentration of the PW until the concentration D3. It was observed that 


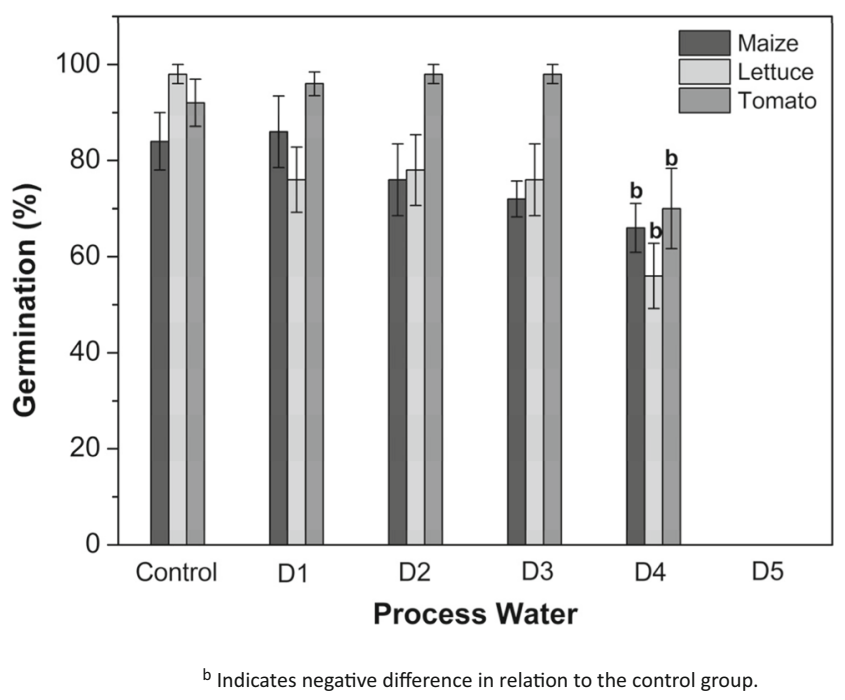

Fig. 2 Percentage of seed germination of maize, lettuce, and tomato after 7 days in response to different concentrations of process water

concentration D4 showed a significant negative effect on the number of seeds germinated for all the studied crops and for D5 concentration, which was regarded as concentrated PW, no germination was observed for any culture evaluated.

It is worth mentioning that although there was a delay in the germination process at the end of 7 days of experiment, the amount of germinated seeds in the control was similar to the amount found for the dilutions D1, D2, and D3, and there was no statistical difference between the dilutions and the control. Therefore, the results suggest that depending on the concentration of PW, it may occur both a delay in the process of germination and also the complete inhibition of germination.

The resistance of the germination process due to changes in the medium may be related to the physiological characteristics of the seeds such as size, permeability of the shell, the difference in the required amounts of each nutrient, and the metabolism and behavior towards the toxic substances that may be present in the medium (Williamns and Hoagland 1982; Mosse et al. 2010). These results corroborate with the GI data (Fig. 3) where the observed variation in the germination velocity of each crop in relation to the PW concentrations studied. The increase of PW concentration occurs from D1 to D5; however, in the graph, only the values of concentrations where seed germination occurred are presented. The GI of sample D5 (concentrated PW) was not used to determine the linear trend because no germination was observed at this concentration for any of the crops tested.

It was observed that the linear tendency of the GI in relation to the process water concentrations as expressed in Fig. 3 is a function of carbon concentration in PW. The carbon concentration in PW was used as a parameter. A decrease of the GI with increase of the PW concentration was observed for all the seeds analyzed indicating a delay in the germination process of the seeds.
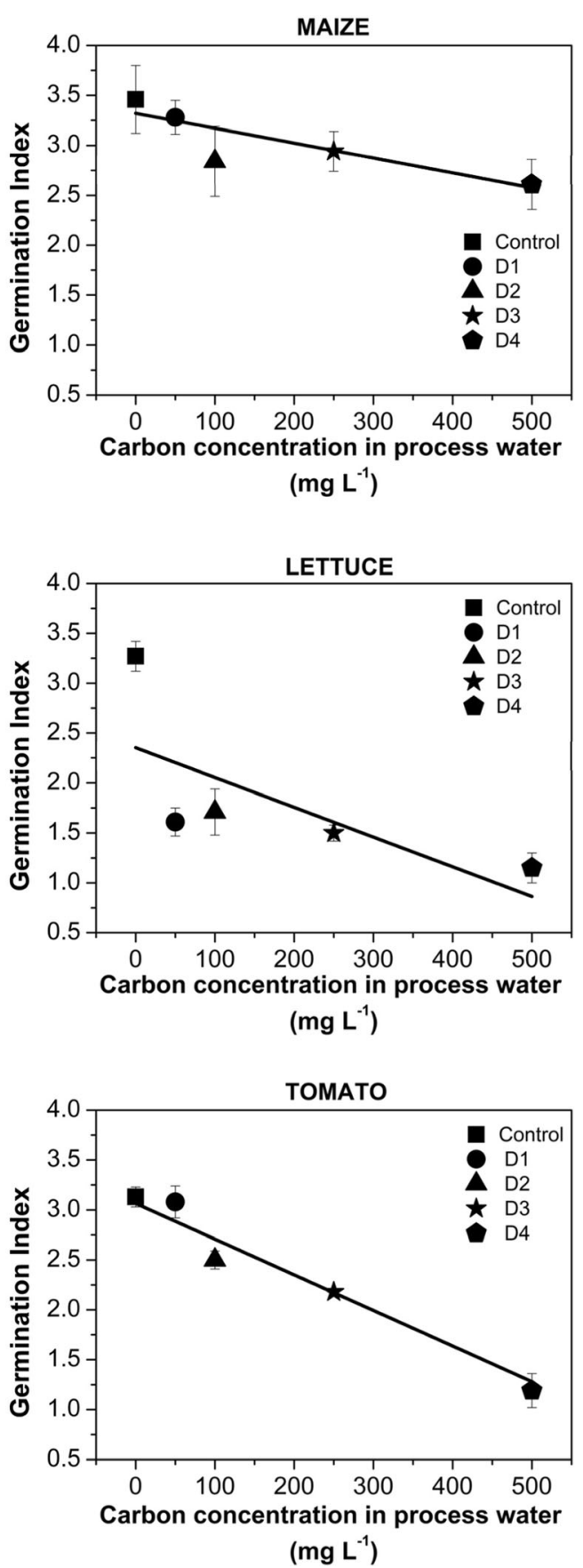

Fig. 3 Correlation of the germination index of maize, lettuce, and tomato seeds with increase of PW concentration expressed as a function of the carbon concentration present in PW

The correlation coefficients of the curves were $0.91,0.71$, and 0.97 for maize, lettuce, and tomato, respectively (Fig. 3). The slopes indicate that the GI of maize is less influenced by PW than other crops. On the other hand, the germination of lettuce decreases in the presence of PW, even for the lowest concentration (D1). For tomato, the decrease in the speed of germination is gradual as the concentration of PW increases. In addition, it is observed that for the concentration D1, the GI 
is close to the GI of the control, indicating that at this concentration, there is no inhibition in the germination process.

Bargmann et al. (2013) evaluated the effect of concentrated process water from different hydrothermal carbonization processes on barley germination and verified a toxic effect for all the analyzed waters, observing both complete inhibition of seed germination and a decrease in the number of germinated seeds. They showed that for the process waters evaluated, the intensity of inhibition was linked to the feedstock used in the carbonization process. A similar result for maize seeds was observed by Vozhdayev et al. (2015) where a decrease in the number of germinated seeds for diluted process water and complete inhibition for concentrated process water were observed. These observations corroborate with those found in this study for dilutions of PW and also for concentrated PW.

In the studies mentioned above, the process water evaluated came from hydrothermal medium produced with water. In this study, the process water was generated through vinasse and sugarcane bagasse carbonization; therefore, the hydrothermal medium was produced by vinasse itself. Vinasse is composed of a complex mixture of organic compounds and ions (potassium, sodium, and magnesium among others) in high concentrations (Bueno et al. 2009; Christofoletti et al. 2013; Marinho et al. 2014; Moraes et al. 2015). Therefore, the resulting PW presents different physicochemical characteristics compared to process waters generated under hydrothermal carbonization when the hydrothermal medium is only water.

It has been reported that the presence of ions such as $\mathrm{K}^{+}$, $\mathrm{Na}^{+}$, and $\mathrm{Ca}^{2+}$ among others may affect the germination process by inhibiting it and negatively influencing the development of the roots (Jafarzadeh and Aliasgharzad 2007). Thus, for the sample D5, the high concentration of these cations (for example, $14.700 \mathrm{mg} \mathrm{L}^{-1}$ of $\mathrm{K}$ and $1.100 \mathrm{mg} \mathrm{L}^{-1} \mathrm{Ca}$ (see Table S1)) was probably one of the factors that limited seed germination. For the diluted PW samples (D1, D2, D3, and D4), the increase in the concentration of these cations, together with the consequent increase in other PW components (e.g., organic compounds), probably influenced the germination process retardation. This observation is in agreement with that observed by Mosse et al. (2010) where increasing concentrations of effluent from wine production which contains high levels of sodium and potassium in addition to organic acids and polyphenols were found to negatively affect the GI. Moreover, such effects could be attributed to the presence of phytotoxic substances, such as organic acids, phenols, and aldehydes, in the process water which are generated during the hydrothermal carbonization process (Kuiters 1989; Kambo and Dutta 2015; Vozhdayev et al. 2015).

Thus, the hypothesis attributed to justify the inhibition/delay of germination and development of seeds tested here is mainly associated with the presence of compounds such as carboxylic and acetic acids, alcohols, and fatty acids (C17 and C18) as well as phenols and furans (Melo et al. 2017b). These compounds were identified by Melo et al. (2017b) in the PW from vinasse and sugarcane bagasse carbonization which occurred under the same conditions used in this study. Further, in sample D5 which is concentrated PW, the highest concentrations of organic compounds and cations are found. Thus, these higher concentrations probably prevented the germination of the seeds. However, for the diluted samples, the lowest concentrations probably contributed only to delay of seed germination. These results are in agreement with those observed by Vozhdayev et al. (2015) who also detected only a decrease in the number of germinated seeds for the diluted process water. As is the case for olive mill wastewater and winery wastewater, PW is a complex matrix composed of organic and inorganic substances and, therefore, it is difficult to specify the compound(s) responsible for such negative observations in relation to the development and germination of seeds (Paredes et al. 1999; Mosse et al. 2010; Pierantozzi et al. 2012). It is reported that phenol can affect negatively root growth, even present in low concentrations, and phenol can also inhibit seed germination (Kuiters 1989; Pinho et al. 2017). Organic acids also are responsible for a decrease in root development, and the increase of chain organic acids is followed by an increase in its toxicity (Kopp et al. 2007; de Tunes et al. 2012; de Assis Alves et al. 2018). This is in agreement with our results, whereas the root was more affected by the presence of different PW concentrations than the shoot, probably because roots were directly in contact with the solutions tested.

The effect of the medium on root development is presented in Fig. 4a which shows the root length measured on the seventh day of the experiment and the different responses among the evaluated seeds. Maize seeds have been used in studies with effluents/pollutants (Sang et al. 2010; Li et al. 2017). Further, maize seeds used with biochar extracts (Sun et al. 2017) showed that the amount of carbon in the medium can improve the process of germination and seedling growth. Sun et al. (2017) attributed the positive effects observed on root growth to the amount of carbon present in the solution extracted from biochar. They compared the development of maize seeds in the solution extracted from biochar to other solutions with similar concentrations of only inorganic ions and observed that the presence of inorganic ions did not influence, negatively or positively, the root development. Therefore, it is understood that the amount of carbon in the PW dilutions probably had a positive influence on the maize root development by stimulating its growth, and the increase of carbon in the medium led to a better development of the roots (as showed in Fig. 4) presenting a positive statistical significance in relation to the control for concentrations D1 $(p=0.0003), \mathrm{D} 2(p=0.001), \mathrm{D} 3(p=0.0003)$, and D4 $(p=$ 0.002 ), as showed in Fig. 4a. Taking into account the carbon concentration present in PW, the effect observed by Sun et al. (2017) would explain the increasing development of maize roots with increasing carbon concentrations in the medium 


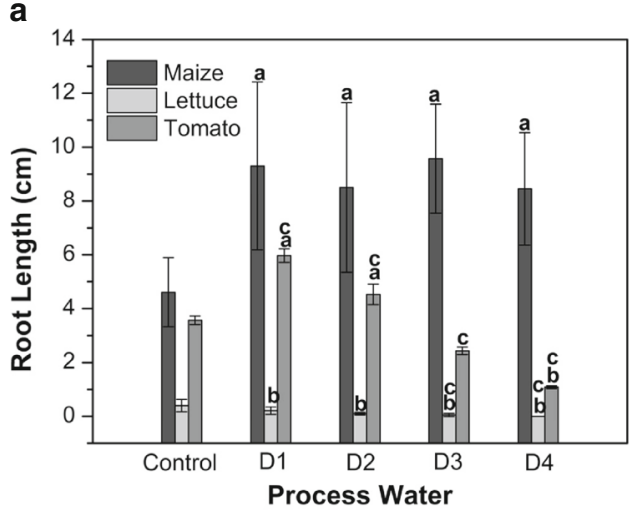

b

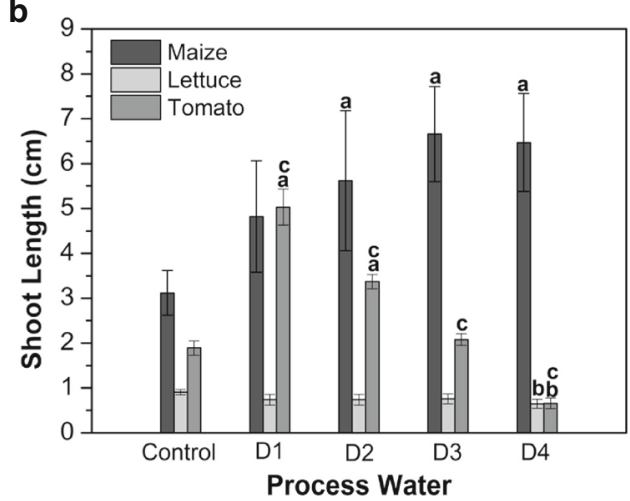

andicates a positive statistical difference in relation to the control; 'Indicates a negative statistical difference in relation to the control; ${ }^{\mathrm{c}}$ Indicates statistical difference between treatments

Fig. 4 Length a of the root and $\mathbf{b}$ shoot at the end of 7 days of experiment for the different process water concentrations

up to D4 dilution since the increase in carbon concentration is also accompanied by an increase in the concentration of organic and inorganic compounds.

Figure 4a shows the negative effect of the presence of PW on the development of lettuce seeds and it was observed that all the dilutions studied presented negative statistical significance when compared to the control showing $p=0.01$ for D1 and $p=0.0001$ for D2, D3, and D4. It is reported that vascular plants, such as lettuce, are more sensitive to variations in the medium such as toxicity which is the reason for their use in toxicological studies to evaluate effluent toxicity (Mosse et al. 2010; Pierantozzi et al. 2012; Young et al. 2012; Priac et al. 2017; Urbano et al. 2017) and to evaluate the presence of substances such as aluminum (Silva and Matos 2016), graphene (Begum et al. 2011), and biochar (Oh et al. 2012) among others. Thereby, it is understood that the reason for lower development of lettuce seeds in comparison to maize and tomato is the sensitivity of this class of plants to the presence of certain compounds which, in turn, inhibited the root growth. The negative impact of shoot and root growth due to aluminum presence was reported by Silva and Matos (2016). The increase in the concentration of $\mathrm{Al}$ by increasing PW concentration (Table S1) could increase the stiffness of the cell wall and affect cellular division, thereby, hindering the growth and development of the roots and shoots, and may be one of the possible causes for the absence of roots in the D4 dilution (Silva and Matos 2016). It is also worth mentioning that the presence of acetic acid in the medium may also influence the growth of lettuce roots. According to Bargmann et al. (2013), the presence of acetic acid would mainly affect root growth. Such observation would also explain the lower development of tomato roots in the D3 concentration where development was close to that observed for the control. For the D1 and D2 dilutions, the root growth of the tomato seeds was shown to be significantly positive in relation to the control. Therefore, it is assumed that concentrations greater than D3, probably in addition to acetic acid and aluminum as well as other organic and inorganic compounds present in the medium, also influenced the development of tomato roots.

The development of the maize shoot was stimulated by the presence of PW in the growth medium. For D2 $(p=0.006)$, D3 $(p=0.0002)$, and D4 $(p=0.0004)$ concentrations, a positive statistical significance was observed in relation to the control, highlighting that D3 concentration showed better results (Fig. 4b). For lettuce, the presence of PW in the medium inhibited the shoot as well as root development and for the sample D4, the development observed was below that of the control. The behavior presented for the tomato roots was also observed for the shoots and the concentration D1 stood out as the one that stimulated better development.

The evaluation of macros and micronutrients present in the agar prepared with the PW dilutions (Table S1) allows a comparison of crop seeds for a single PW application via fertigation. A good development of maize crop requires $41-$ $78 \mathrm{mg} \mathrm{L}^{-1}$ of potassium, 5-16 $\mathrm{mg} \mathrm{L}^{-1}$ of Ca, and 5-16 $\mathrm{mg} \mathrm{L}^{-1}$ of $\mathrm{Mg}$ (Coelho 2006). In this case, the amount of $\mathrm{K}$ present in the concentration D1 corresponds to the amount required by the crop. For calcium, the amounts required for maize are present at the D3 concentration and for magnesium, the amount present in all PW concentrations is below the indicated range. Magnesium requirements are met at concentrations D4 and D5 whereas those of Fe only at D3.

For a good development, vegetables generally require, from the growth medium, about $32-80 \mathrm{mg} \mathrm{L}^{-1}$ of $\mathrm{P}, 115 \mathrm{mg} \mathrm{L}^{-1}$ of $\mathrm{K}$, $3 \mathrm{mg} \mathrm{L}^{-1}$ of $\mathrm{Zn}, 2 \mathrm{mg} \mathrm{L}^{-1}$ of Cu (Carrijo et al. 2004), in addition to $71 \mathrm{mg} \mathrm{L}^{-1}$ of $\mathrm{N}, 67 \mathrm{mg} \mathrm{L}^{-1}$ of $\mathrm{Ca}$, and $54 \mathrm{mg} \mathrm{L}^{-1}$ of $\mathrm{Mg}$ for tomato, and $74 \mathrm{mg} \mathrm{L}^{-1}$ of $\mathrm{N}, 41 \mathrm{mg} \mathrm{L}^{-1}$ of $\mathrm{Ca}$, and $13 \mathrm{mg} \mathrm{L}{ }^{-1} \mathrm{Mg}$ for lettuce (Trani et al. 2011). Therefore, comparing the medium prepared with $\mathrm{PW}$ dilutions and agar in petri dishes to the concentrations D1 and D2 of PW, the concentration of K present (Table S1) was within the recommended range. The concentrations of the micronutrients $\mathrm{Zn}$ and $\mathrm{Cu}$ in the different dilutions of PW were below the recommended levels.

Thus, when evaluating only one application of PW, the dilutions evaluated were capable of meeting the specific needs of some elements. In order for PW to reach the needs of all nutrients, it is understood that successive applications of PW 
are required. The evaluation of the presented results also suggests that the application of PW during other stages of crop growth should be studied. Other authors have already observed the efficiency of similar effluents for the process of plant growth (Soni et al. 2014) and even though a delay in the germination process is observed, it is necessary to identify the optimal moment of the development stage for PW use in order to obtain the best benefits. Therefore, for maize seeds, although germination delay was observed, the percentage of germination was not affected in the D3 concentration which also presented better root and shoot development. For tomato seeds, the concentration D1 was the one that best stimulated its development across all parameters analyzed. For lettuce, the PW presented a toxic effect in all the evaluated concentrations as evidenced by the decrease in the percentage of germinated seeds in relation to the control and also by the low development of roots and shoots.

\section{Lethality of Artemia salina nauplii evaluation}

The exposure of Artemia salina nauplii to PW concentration of $10 \mathrm{mg} \mathrm{C} \mathrm{L}^{-1}$ as well as the control did not cause any death. Exposure of individuals to a concentration of $100 \mathrm{mg} \mathrm{C} \mathrm{\textrm {L } ^ { - 1 }}$ resulted in the death of only one individual. On the other hand, the exposure of nauplii to a concentration of $1000 \mathrm{mg} \mathrm{C} \mathrm{L}^{-1}$ triggered the death of all individuals (Fig. 5). These tests allowed to calculate the $\mathrm{LC}_{50}$ which was $185 \mathrm{mg} \mathrm{C} \mathrm{L}^{-1}$.

Nauplii from control presented a typical morphology, including dilatation of the intestine and a translucent lumen (Fig. 6a) with no particles on the surface of the abdomen (Fig. 6b) and a few particles from the culture medium attached to the antennas (Fig. 6c). The exposure of nauplii to $10 \mathrm{mg} \mathrm{C} \mathrm{L}^{-1}$ $\mathrm{PW}$ began to induce structural changes in the individuals.

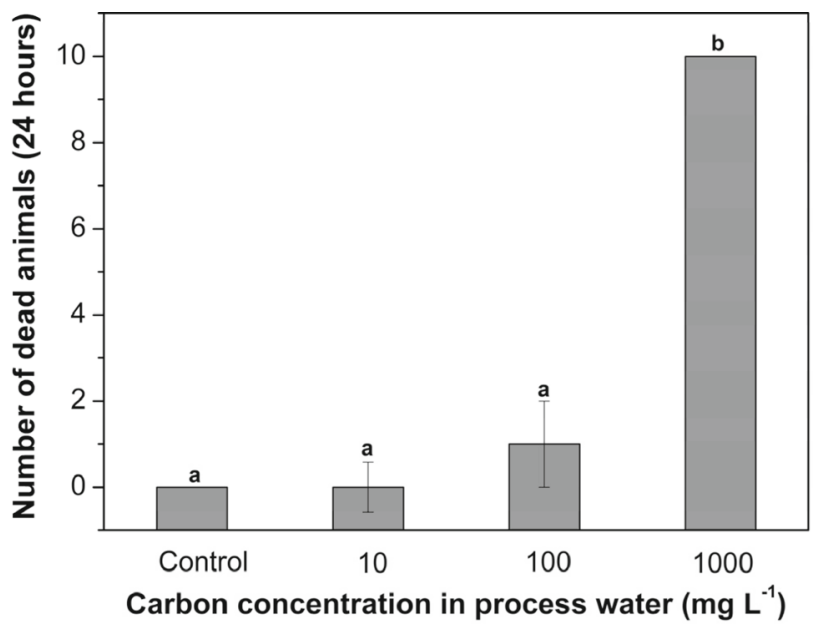

${ }^{\mathrm{a}}$ Indicates that there was no statistical difference in relation to the control; ${ }^{\mathrm{b}}$ Indicates that there was statistical difference in relation to the control.

Fig. 5 Evaluation of the process water toxicity using Artemia salina nauplii as an experimental model
Dilatation of the digestive tract (Fig. 6d) was observed although few particles were visualized in the abdomen (Fig. 6e) or gills (Fig. 6f). Nauplii exposed to $100 \mathrm{mg} \mathrm{C} \mathrm{L}^{-1}$ exhibited dilatation of the digestive tract as well an accumulation of dense material (Fig. 6g). However, little material accumulated on the surface of the abdomen (Fig. 6h) and antennas (Fig. 6i). In the individuals exposed to $1000 \mathrm{mg} \mathrm{C} \mathrm{L}^{-1}$, considerable morphological damage was observed. The digestive tract was dilated with an abundance of dense material inside and severe damage to the antennas (Fig. 6j/l) as well a large accumulation of material on the surface of the abdomen (Fig. 6j/k). However, the process water from the hydrothermal carbonization of vinasse and sugarcane bagasse can be considered practically non-toxic. This conclusion is based on the proposal of GESAMP (2002) in reference to the marine environment where substances with $\mathrm{LC}_{50}$ greater than 100 and less than $10,000 \mathrm{mg} \mathrm{L}^{-1}$ are considered practically non-toxic.

Although PW did not cause any death at $10 \mathrm{mg} \mathrm{C} \mathrm{L}^{-1}$ concentration and only one death at $100 \mathrm{mg} \mathrm{C} \mathrm{L}^{-1}$, the PW triggered structural changes, such as dilatation of the digestive tube, accumulation of dense material in its interior, and damage to antennas in Artemia, at these two concentrations. Such structural changes have also been described for other nanostructured materials. In this regard, Ozkan et al. (2016) observed structural changes in Artemias exposed to $\mathrm{TiO}_{2}$ and $\mathrm{AgTiO}_{2}$ nanoparticles. Further, Madhav et al. (2017) found structural alterations in individuals exposed to copper nanoparticles.

\section{Conclusion}

The concentrated process water (PW) from hydrothermal carbonization of vinasse and sugarcane bagasse inhibited the germination process of maize, lettuce, and tomato seeds. However, at lower concentrations, PW delayed the germination process but did not make the germination process unfeasible. The response to the studied concentrations varied among the crops evaluated indicating it to be specie-dependent. For maize, the concentration D3 stimulated the development of roots and shoot. For tomato, the best concentration of PW was D1 which was shown to improve its development. For lettuce, all concentrations studied showed a negative effect.

Therefore, it is understood that the process water from vinasse and sugarcane bagasse hydrothermal carbonization was toxic to seed germination; however, the toxic effects observed were minimized in the dilutions and if the PW is applied in specific quantities, it may be potentially used as a fertilizer to provide the necessary nutrients for the initial development of the plant and to promote root and shoot elongation. In addition, the tests using Artemia indicated that the $\mathrm{LC}_{50}$ of process water from the hydrothermal carbonization of the vinasse and 
Fig. 6 Optical and SEM of Artemia salina nauplii exposed to process water toxicity tests

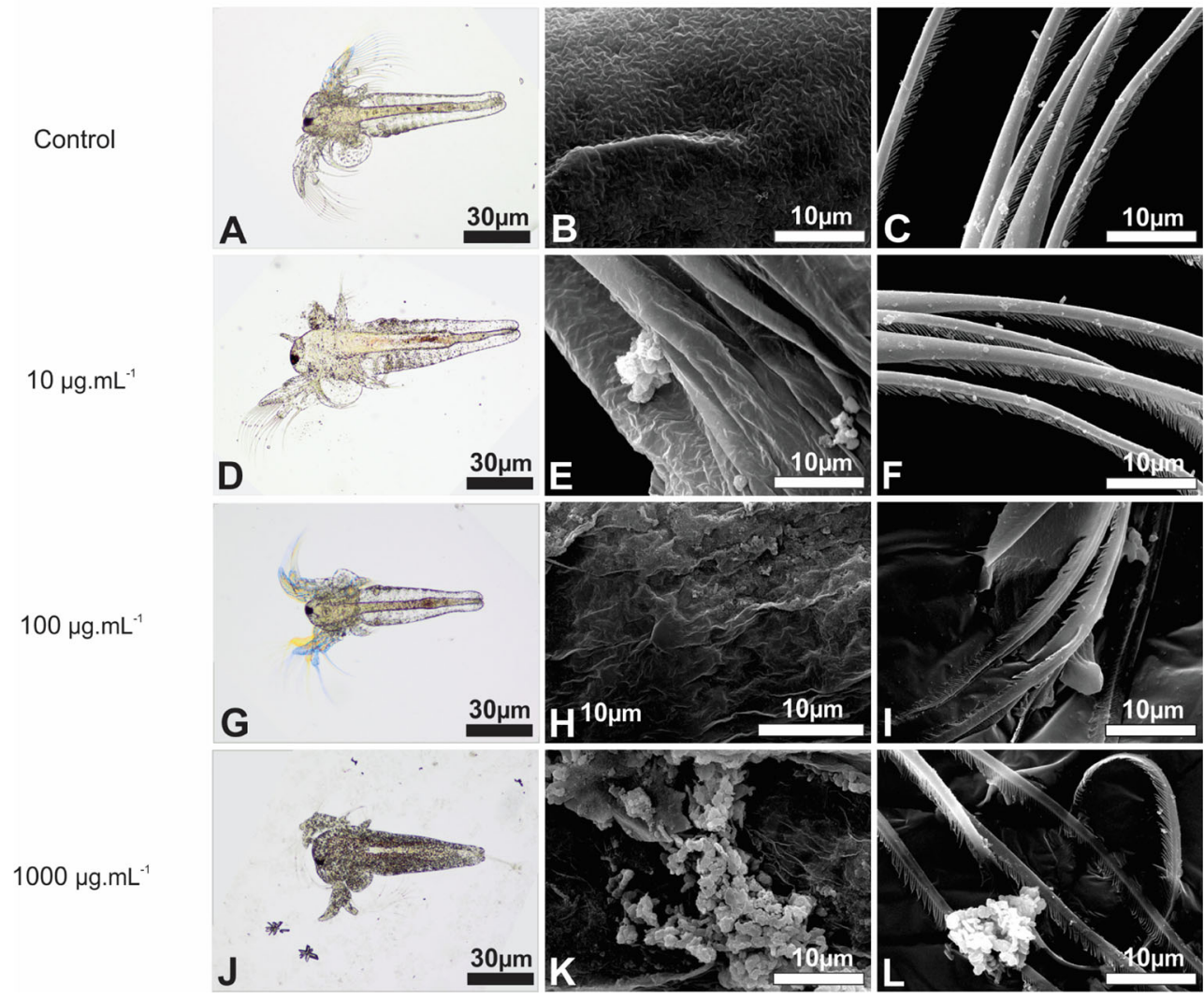

sugarcane bagasse is characteristic of practically non-toxic material/substances. However, PW caused morphological damage in Artemia, mainly in the digestion tube and in the antennas, at the concentration of $1000 \mathrm{mg} \mathrm{C} \mathrm{L}^{-1}$.

Therefore, our results suggest that more detailed studies should be carried out to understand the toxicity of the process waters from hydrothermal carbonization as its composition can vary from process to process, and the results may be different for each crop.

Acknowledgements The authors would like to thank the Central Analítida-UFC/CT-INFRA/MCTI-SISNANO/Pró-Equipamentos CAPES. The authors also appreciate the scholarship from the Coordenação de Aperfeiçoamento de Pessoal de Nível Superior (CAPES).

Funding information O. P. F acknowledged the support from the Fundação Cearense de Apoio ao Desenvolvimento Científico e Tecnológico (FUNCAP) (PRONEX PR2-0101-00006.01.00/15) and from CAPES-PROCAD 2013 Grant 183995. M. C. B. acknowledged the support from the Conselho Nacional de Desenvolvimento Científico e Tecnológico (CNPq) grants 445487/2014-3 and 307925/2012-9 and Fundação de Amparo à Pesquisa do Estado de São Paulo (FAPESP) (2015/22954-1). A. B. M. acknowledged the support from the Fundação de Amparo à Pesquisa do Estado de São Paulo (FAPESP) (2014/17511-0).

\section{References}

Bargmann I, Rillig MC, Buss W, Kruse A, Kuecke M (2013) Hydrochar and biochar effects on germination of spring barley. J Agron Crop Sci 199:360-373. https://doi.org/10.1111/jac.12024

Bargmann I, Rillig MC, Kruse A, Greef JM, Kücke M (2014) Effects of hydrochar application on the dynamics of soluble nitrogen in soils and on plant availability. J Plant Nutr Soil Sci 177:48-58. https://doi.org/10.1002/jpln.201300069

Begum P, Ikhtiari R, Fugetsu B (2011) Graphene phytotoxicity in the seedling stage of cabbage, tomato, red spinach, and lettuce. Carbon 49: 3907-3919. https://doi.org/10.1016/j.carbon.2011.05.029

Bhattacharya J, Khuspe SS (2001) In vitro and in vivo germination of papaya (Carica papaya L.) seeds. Sci Hortic. https://doi.org/10. 1016/S0304-4238(01)00237-0

Biller P, Ross AB, Skill SC, Lea-Langton A, Balasundaram B, Hall C, Riley R, Llewellyn CA (2012) Nutrient recycling of aqueous phase for microalgae cultivation from the hydrothermal liquefaction process. Algal Res 1:70-76. https://doi.org/10.1016/j.algal.2012.02.002

Bueno PC, Antonio J, Rubí M et al (2009) Impacts caused by the addition of wine vinasse on some chemical and mineralogical properties of a Luvisol and a Vertisol in La Mancha (Central Spain). J Soils Sediments 9:121-128. https://doi.org/10.1007/s11368-009-0074-0

Cançado PHD, Ferreira T, Piranda EM, Soares CO (2013) Sugarcane stems as larval habitat for the stable fly (stomoxys calcitrans) in sugarcane plantations. Pesqui Vet Bras 33:741-744. https://doi. org/10.1590/S0100-736X2013000600009 
Carrijo OA, de Souza RB, Marouelli WA, de Andrade RJ (2004) Fertirrigação de Hortaliças. In: 32 Circular Técnica. EMBRAPA, pp 1-13

Christofoletti CA, Escher JP, Correia JE, Marinho JFU, Fontanetti CS (2013) Sugarcane vinasse: environmental implications of its use. Waste Manag 33:2752-2761. https://doi.org/10.1016/j.wasman.2013.09.005

Coelho AM (2006) Nutrição e Adubação do Milho. In: 78 Circular Técnica, 1st edn. EMBRAPA, Sete Lagoas, pp 10

de Assis Alves T, Fontes Pinheiro P, Miranda Praça-Fontes M, Fonseca Andrade-Vieira L, Barelo Corrêa K, de Assis Alves T, da Cruz FA, Lacerda Júnior V, Ferreira A, Bastos Soares TC (2018) Toxicity of thymol, carvacrol and their respective phenoxyacetic acids in Lactuca sativa and Sorghum bicolor. Ind Crop Prod 114:59-67. https://doi.org/10.1016/j.indcrop.2018.01.071

De Oliveira BG, Carvalho JLN, Cerri CEP et al (2013) Soil greenhouse gas fluxes from vinasse application in Brazilian sugarcane areas. Geoderma 200-201:77-84. https://doi.org/10. 1016/j.geoderma.2013.02.005

de Souza Dias MO, Maciel Filho R, Mantelatto PE et al (2015) Sugarcane processing for ethanol and sugar in Brazil. Environ Dev 15:35-51. https://doi.org/10.1016/j.envdev.2015.03.004

de Tunes LM, Avelar SAG, Barros ACSA et al (2012) Critical levels of organic acids on seed germination and seedling growth of wheat. Rev Bras Sementes 34:366-372. https://doi.org/10.1590/S010131222012000300002

Du Z, Hu B, Shi A et al (2012) Cultivation of a microalga Chlorella vulgaris using recycled aqueous phase nutrients from hydrothermal carbonization process. Bioresour Technol 126:354-357. https://doi.org/10.1016/j.biortech.2012.09.062

Embrapa (2000) Determinações Analíticas. In: do Carmo CAF de S, de Araújo WS, Bernardi AC de C, Saldanha MFC (eds) Métodos de análise de tecidos vegetais utlizados na Embrapa Solos. Embrapa Solos, Rio de Janeiro, p 47

Fang J, Gao B, Chen J, Zimmerman AR (2015) Hydrochars derived from plant biomass under various conditions: characterization and potential applications and impacts. Chem Eng J 267:253-259. https://doi.org/10.1016/j.cej.2015.01.026

Finney DJ (1971) Probit analysis. Cambridge University Press, Cambridge, p 333

Funke A, Ziegler F (2010) Hydrothermal carbonization of biomass: a summary and discussion of chemical mechanisms for process engineering. Biofuels Bioprod Biorefin 4:160 177. https://doi.org/10.1002/bbb.198

George C, Wagner M, Kücke M, Rillig MC (2012) Divergent consequences of hydrochar in the plant-soil system: arbuscular mycorrhiza, nodulation, plant growth and soil aggregation effects. Appl Soil Ecol 59:68-72. https://doi.org/10.1016/j.apsoil.2012.02.021

GESAMP (2002) The revised GESAMP hazard evaluation procedure for chemical substances carried by ships, 1st edn. IMO, London

Gonçalves SPC, Strauss M, Delite FS, Clemente Z, Castro VL, Martinez DST (2016) Activated carbon from pyrolysed sugarcane bagasse: silver nanoparticle modification and ecotoxicity assessment. Sci Total Environ 565:833-840. https://doi.org/10.1016/j.scitotenv. 2016.03.041

Hofsetz K, Silva MA (2012) Brazilian sugarcane bagasse: energy and non-energy consumption. Biomass Bioenergy 46:564-573. https:// doi.org/10.1016/j.biombioe.2012.06.038

Hognon C, Delrue F, Texier J, Grateau M, Thiery S, Miller H, Roubaud A (2015) Comparison of pyrolysis and hydrothermal liquefaction of Chlamydomonas reinhardtii. Growth studies on the recovered hydrothermal aqueous phase. Biomass Bioenergy 73:23-31. https://doi.org/10.1016/j. biombioe.2014.11.025

Jafarzadeh AA, Aliasgharzad N (2007) Salinity and salt composition effects on seed germination and root length of four sugar beet cultivars. Biologia 62:562-564. https://doi.org/10.2478/ s11756-007-0111-7

Jelvez Serra NS, Goulart HF, Triana MF et al (2017) Identification of stable fly attractant compounds in vinasse, a byproduct of sugarcane-ethanol distillation. Med Vet Entomol 31:381-391. https://doi.org/10.1111/mve.12246

Joppert CL, Marilin M, Costa HKM, Sim R (2017) Biomass and bioenergy energetic shift of sugarcane bagasse using biogas produced from sugarcane vinasse in Brazilian ethanol plants

Kabadayi Catalkopru A, Kantarli IC, Yanik J (2017) Effects of spent liquor recirculation in hydrothermal carbonization. Bioresour Technol 226:89-93. https://doi.org/10.1016/j.biortech.2016.12.015

Kambo HS, Dutta A (2015) A comparative review of biochar and hydrochar in terms of production, physico-chemical properties and applications. Renew Sust Energ Rev 45:359-378. https://doi.org/10.1016/j.rser.2015.01.050

Kambo HS, Minaret J, Dutta A (2017) Process water from the hydrothermal carbonization of biomass: a waste or a valuable product? Waste Biomass Valoriz 1-9. https://doi.org/10.1007/s12649-017-9914-0

Kopp MM, Kopp V, Luiz J, Coimbra M (2007) Níveis críticos dos ácidos acético, propiônico e butírico para estudos de toxicidade em arroz em solução nutritiva. Acta Bot Bras 21:147-154. https://doi.org/10. 1590/S0102-33062007000100014

Kuiters AT (1989) Effects of phenolic acids on germination and eraly growth of herbaceous woodland plants. J Chem Ecol 15:467-479

Li G, Chen J, Yan W, Sang N (2017) A comparison of the toxicity of landfill leachate exposure at the seed soaking and germination stages on Zea mays L. (maize). J Environ Sci (China) 55: 206-213. https://doi.org/10.1016/j.jes.2016.06.031

Libra J, Ro KS, Kammann C et al (2011) Hydrothermal carbonization of biomass residuals: a comparative review of the chemistry, processes and applications of wet and dry pyrolysis. Biofuels 2:71-106. https://doi.org/10.4155/bfs.10.81

Lu X, Flora JRV, Berge ND (2014) Influence of process water quality on hydrothermal carbonization of cellulose. Bioresour Technol 154: 229-239. https://doi.org/10.1016/j.biortech.2013.11.069

Lucian M, Fiori L (2017) Hydrothermal carbonization of waste biomass: process design, modeling, energy efficiency and cost analysis. Energies. https://doi.org/10.3390/en10020211

Madhav MR, David SEM, Kumar RSS, Swathy JS, Bhuvaneshwari M, Mukherjee A, Chandrasekaran N (2017) Toxicity and accumulation of copper oxide $(\mathrm{CuO})$ nanoparticles in different life stages of Artemia salina. Environ Toxicol Pharmacol 52:227238. https://doi.org/10.1016/j.etap.2017.03.013

Maguire JD (1962) Speed of germination - aid in selection and evaluation for seedling emergence and vigor. Croop Sci 2:176-177

Marinho JFU, Correia JE, Marcato ACDC et al (2014) Sugar cane vinasse in water bodies: impact assessed by liver histopathology in tilapia. Ecotoxicol Environ Saf 110C:239245. https://doi.org/10.1016/j.ecoenv.2014.09.010

Melo CA, Junior FHS, Bisinoti MC, Moreira AB, Ferreira OP (2017a) Transforming sugarcane bagasse and vinasse wastes into hydrochar in the presence of phosphoric acid: an evaluation of nutrient contents and structural properties. Waste Biomass Valoriz 8:1139-1151. https://doi.org/10.1007/s12649-016-9664-4

Melo CDA, Julio RC, Laranja MJ, et al (2017b) Identification of organic compounds in the products obtained from the hydrothermal carbonization of sugarcane bagasse and vinasse. In: IUPAC 2017, pp 1

Melo TM, Bottlinger M, Schulz E, Leandro WM, de Aguiar Filho AM, Ok YS, Rinklebe J (2017c) Effect of biosolid hydrochar on toxicity to earthworms and brine shrimp. Environ Geochem Health 39:1-14. https://doi.org/10.1007/s10653-017-9995-5

Meyer B, Ferrigni N, Putnam J, Jacobsen L, Nichols D, McLaughlin J (1982) Brine shrimp: a convenient general bioassay for active plant constituents. Planta Medica 45(05):31-34 
Moraes BS, Zaiat M, Bonomi A (2015) Anaerobic digestion of vinasse from sugarcane ethanol production in Brazil: challenges and perspectives. Renew Sust Energ Rev 44:888-903. https://doi.org/10.1016/j.rser.2015.01.023

Mosse KPM, Patti AF, Christen EW, Cavagnaro TR (2010) Winery wastewater inhibits seed germination and vegetative growth of common crop species. J Hazard Mater 180:63-70. https://doi.org/10.1016/j.jhazmat.2010.02.069

Oh TK, Shinogi Y, Chikushi J et al (2012) Effect of aqueous extract of biochar on germination and seedling growth of lettuce (Lactuca sativa L.) J Fac Agric Kyushu Univ 57:55-60

Oliveira I, Blöhse D, Ramke HG (2013) Hydrothermal carbonization of agricultural residues. Bioresour Technol 142:138-146. https://doi.org/10.1016/j.biortech.2013.04.125

Ozkan Y, Altinok I, Ilhan H, Sokmen M (2016) Determination of $\mathrm{TiO}_{2}$ and $\mathrm{AgTiO}_{2}$ nanoparticles in artemia salina: toxicity, morphological changes, uptake and depuration. Bull Environ Contam Toxicol 96(1):36-42

Paredes C, Cegarra J, Roig A, Bernal MP (1999) Characterization of olive mill wastewater (alpechin) and its sludge for agricultural purposes. Bioresour Technol 67:111-115

Parshetti GK, Liu Z, Jain A, Srinivasan MP, Balasubramanian R (2013) Hydrothermal carbonization of sewage sludge for energy production with coal. Fuel 111:201-210. https://doi.org/10.1016/j.fuel.2013.04.052

Pierantozzi P, Zampini C, Torres M, Isla MI, Verdenelli RA, Meriles JM, Maestri D (2012) Physico-chemical and toxicological assessment of liquid wastes from olive processing-related industries. J Sci Food Agric 92:216-223. https://doi.org/10.1002/jsfa.4562

Pinho IA, Lopes DV, Martins RC, Quina MJ (2017) Phytotoxicity assessment of olive mill solid wastes and the influence of phenolic compounds. Chemosphere 185:258-267. https://doi. org/10.1016/j.chemosphere.2017.07.002

Poerschmann J, Weiner B, Wedwitschka H, Baskyr I, Koehler R, Kopinke FD (2014) Characterization of biocoals and dissolved organic matter phases obtained upon hydrothermal carbonization of brewer's spent grain. Bioresour Technol 164:162-169. https://doi.org/10.1016/j.biortech.2014.04.052

Priac A, Badot P-M, Crini G (2017) Treated wastewater phytotoxicity assessment using Lactuca sativa: focus on germination and root elongation test parameters. Comptes Rendus Biologies 340:188194. https://doi.org/10.1016/j.crvi.2017.01.002

Reibe K, Götz K-P, Roß C-L, Döring TF, Ellmer F, Ruess L (2015) Impact of quality and quantity of biochar and hydrochar on soil Collembola and growth of spring wheat. Soil Biol Biochem 83: 84-87. https://doi.org/10.1016/j.soilbio.2015.01.014

Rezende C, de Lima M, Maziero P, deAzevedo E, Garcia W, Polikarpov I (2011) Chemical and morphological characterization of sugarcane bagasse submitted to a delignification process for enhanced enzymatic digestibility. Biotechnol Biofuels 4:54. https://doi.org/10.1186/1754-6834-4-54

Rillig MC, Wagner M, Salem M, Antunes PM, George C, Ramke HG, Titirici MM, Antonietti M (2010) Material derived from hydrothermal carbonization: effects on plant growth and arbuscular mycorrhiza. Appl Soil Ecol 45:238242. https://doi.org/10.1016/j.apsoil.2010.04.011

Ross AB, Biller P, Kubacki ML, Li H, Lea-Langton A, Jones JM (2010) Hydrothermal processing of microalgae using alkali and organic acids. Fuel 89:2234-2243. https://doi.org/10.1016/j.fuel.2010.01.025

Salem M, Kohler J, Wurst S, Rillig MC (2013) Earthworms can modify effects of hydrochar on growth of Plantago lanceolata and performance of arbuscular mycorrhizal fungi. Pedobiologia 56:219-224. https://doi.org/10.1016/j.pedobi.2013.08.003

Sang N, Han M, Li G, Huang M (2010) Landfill leachate affects metabolic responses of Zea mays L. seedlings. Waste Manag 30:856862. https://doi.org/10.1016/j.wasman.2010.01.023
Silva P, Matos M (2016) Assessment of the impact of aluminum on germination, early growth and free proline content in Lactuca sativa L. Ecotoxicol Environ Saf 131:151-156. https://doi.org/10.1016/j. ecoenv.2016.05.014

Silva CC, Melo CA, Soares Junior FH, Moreira AB, Ferreira OP, Bisinoti MC (2017) Effect of the reaction medium on the immobilization of nutrients in hydrochars obtained using sugarcane industry residues. Bioresour Technol 237:213-221. https://doi.org/10.1016/j.biortech.2017.04.004

Sindhu R, Gnansounou E, Binod P, Pandey A (2016) Bioconversion of sugarcane crop residue for value added products e an overview. Renew Energy 98:203-215. https://doi.org/10.1016/j.renene.2016.02.057

Soni N, Leon RG, Erickson JE, Ferrell JA, Silveira ML, Giurcanu MC (2014) Vinasse and biochar effects on germination and growth of palmer Amaranth (Amaranthus palmeri), sicklepod (Senna obtusifolia), and southern crabgrass (Digitaria ciliaris). Weed Technol 28:694-702. https://doi.org/10.1614/WT-D-14-00044.1

Stemann J, Ziegler F (2011) Assessment of the energetic efficiency of a continuously operating plant for hydrothermal carbonisation of biomass. World Renewable Energy Congress 2011, Sweden, pp 125132. https://doi.org/10.3384/ecp11057125

Stemann J, Erlach B, Ziegler F (2013) Hydrothermal carbonisation of empty palm oil fruit bunches: laboratory trials, plant simulation, carbon avoidance, and economic feasibility. Waste Biomass Valoriz 4:441-454. https://doi.org/10.1007/s12649-012-9190-y

Sun J, Drosos M, Mazzei P, Savy D, Todisco D, Vinci G, Pan G, Piccolo A (2017) The molecular properties of biochar carbon released in dilute acidic solution and its effects on maize seed germination. Sci Total Environ 576:858-867. https://doi.org/10.1016/j.scitotenv.2016.10.095

Tekin K, Karagöz S, Bektaș S (2013) Hydrothermal conversion of woody biomass with disodium octaborate tetrahydrate and boric acid. Ind Crop Prod 49:334-340. https://doi.org/10.1016/j.indcrop.2013.05.014

Trani PE, Tivelli SW, Carrijo OA (2011) Boletim Técnico n¹96: Fertirrigação em Hortaliças, 2nd edn. Instituto Agronômico (IAC), Campinas

Urbano VR, Mendonça TG, Bastos RG, Souza CF (2017) Effects of treated wastewater irrigation on soil properties and lettuce yield. Agric Water Manag 181:108-115. https://doi.org/10. 1016/j.agwat.2016.12.001

US EPA (1992) Acid digestion of aqueous samples and extracts for total metals for analysis by FLAA or ICP spectroscopy. In: Test Methods for Evaluating Solid Waste, Phiysical/Chemical Methods (SW-846). pp 1-5

Vozhdayev GV, Spokas KA, Molde JS, Heilmann SM, Wood BM, Valentas KJ (2015) Response of maize germination and growth to hydrothermal carbonization filtrate type and amount. Plant Soil 396: 127-136. https://doi.org/10.1007/s11104-015-2577-3

Weiner B, Poerschmann J, Wedwitschka H, Koehler R, Kopinke FD (2014) Influence of process water reuse on hydrothermal carbonization of paper. ACS Sustain Chem Eng 2:21652171. https://doi.org/10.1021/sc500348v

Williamns RD, Hoagland RE (1982) The effects of naturally occurring phenolic compounds on seed germination. Weed Sci 30:206-212

Yoshimura M, Byrappa K (2008) Hydrothermal processing of materials: past, present and future. J Mater Sci 43:2085-2103. https://doi.org/10.1007/s10853-007-1853-x

Young BJ, Riera NI, Beily ME, Bres PA, Crespo DC, Ronco AE (2012) Toxicity of the effluent from an anaerobic bioreactor treating cereal residues on Lactuca sativa. Ecotoxicol Environ Saf 76:182-186. https://doi.org/10.1016/j.ecoenv.2011.09.019

Zhou L, Xia M, Wang L, Mao H (2016) Toxic effect of perfluorooctanoic acid (PFOA) on germination and seedling growth of wheat (Triticum aestivum L.) Chemosphere 159: 420-425. https://doi.org/10.1016/j.chemosphere.2016.06.045 